\title{
Fibulin-3 levels in malignant pleural mesothelioma are associated with prognosis but not diagnosis
}

Michaela B Kirschner ${ }^{*}, 1,2,13$, Emily Pulford ${ }^{3}$, Mir Alireza Hoda ${ }^{4}$, Anita Rozsas ${ }^{4}$, Kim Griggs ${ }^{3}$, Yuen Yee Cheng ${ }^{1}$, J James B Edelman ${ }^{5}$, Steven C Kao ${ }^{1,6}$, Rebecca Hyland ${ }^{1}$, Yawen Dong ${ }^{4}$, Viktoria László ${ }^{4}$, Thomas Klikovits ${ }^{4}$, Michael P Vallely $2,5,7$, Michael Grusch ${ }^{8}$, Balazs Hegedus ${ }^{4,9}$, Balazs Dome ${ }^{4,10,11,12}$, Walter Klepetko ${ }^{4}$, Nico van Zandwijk ${ }^{1,2}$, Sonja Klebe ${ }^{3}$ and Glen Reid ${ }^{1,2}$

${ }^{1}$ Asbestos Diseases Research Institute (ADRI), Sydney, NSW 2139, Australia; ${ }^{2}$ Sydney Medical School, The University of Sydney, Sydney, NSW 2006, Australia; ${ }^{3}$ Department of Anatomical Pathology, Flinders University and SA Pathology, Adelaide, SA 5042, Australia; ${ }^{4}$ Translational Thoracic Oncology Laboratory, Division of Thoracic Surgery, Department of Surgery, Comprehensive Cancer Center Vienna, Medical University of Vienna, 1090 Vienna, Austria; ${ }^{5}$ Cardiothoracic Surgical Unit, Royal Prince Alfred Hospital; The Baird Institute; The University of Sydney, Sydney, NSW 2050, Australia; ${ }^{6}$ Department of Medical Oncology, Chris O'Brien Lifehouse, Sydney, NSW 2050, Australia; ${ }^{7}$ Australian School of Advanced Medicine, Macquarie University, Sydney, NSW 2109, Australia; ${ }^{8}$ Department of Medicine I, Institute of Cancer Research, Medical University of Vienna, 1090 Vienna, Austria; ${ }^{9}$ MTASE Molecular Oncology Research Group, Hungarian Academy of Sciences, 1051 Budapest, Hungary; ${ }^{10}$ Department of Biomedical Imaging and Image-guided Therapy, Division of Molecular and Gender Imaging, Medical University of Vienna, 1090 Vienna, Austria; ${ }^{11}$ Department of Thoracic Surgery, National Institute of Oncology, 1122 Budapest, Hungary and ${ }^{12}$ Department of Tumor Biology, National Koranyi Institute of Pulmonology and Semmelweis University, 1085 Budapest, Hungary

Background: Fibulin-3 (FBLN3) was recently presented as a promising novel biomarker for malignant pleural mesothelioma (MPM), warranting independent validation studies.

Methods: ELISA was used to measure cellular and secreted FBLN3 in cell lines, in plasma of xenograft tumour-bearing mice, in plasma from two independent series of MPM and non-MPM patients and in pleural fluid from a third series. Diagnostic and prognostic potential of FBLN3 was assessed by receiver operating characteristics curve analysis and Kaplan-Meier method, respectively.

Results: FBLN3 was expressed in all MPM and benign mesothelial cell lines tested, and a correlation was observed between cellular protein expression and secreted levels. Human FBLN3 was detectable in plasma of tumour-bearing mice, suggesting that MPM cells contribute to levels of circulating FBLN3. Plasma FBLN3 was significantly elevated in MPM patients from the Sydney cohort, but not the Vienna cohort, but the diagnostic accuracy was low (63\%, (95\% Cl: 50.1-76.4) and 56\% (95\% Cl: 41.5-71.0), respectively). Although FBLN3 levels in pleural effusions were not significantly different between cases and controls, FBLN3 levels in pleural effusion fluid were found to be independently associated with prognosis (hazard ratio of 9.92 (95\% Cl: 2.14-45.93)).

Conclusions: These data confirm the potential prognostic value of pleural effusion FBLN3, but question the diagnostic value of this protein in MPM patients.

${ }^{*}$ Correspondence: Dr MB Kirschner; E-mail: michaela.kirschner@usz.ch
${ }^{13}$ Current address: Division of Thoracic Surgery, University Hospital Zurich, 8091 Zurich, Switzerland

Received 25 March 2015; revised 10 July 2015; accepted 14 July 2015; published online 11 August 2015

(c) 2015 Cancer Research UK. All rights reserved 0007-0920/15 
Fibulin-3 (FBLN3), encoded by the EGF-containing fibulin-like extracellular matrix protein 1 (EFEMP1) gene, is a member of the fibulin family of secreted extracellular glycoproteins that are characterised by a tandem repeat of EGF-like domains and a unique C-terminal fibulin-like module (Timpl et al, 2003; Zhang and Marmorstein, 2010; Zhou, 2013). The fibulin family forms part of the extracellular matrix (ECM) where they contribute to the stabilisation of supramolecular structures such as elastic fibres and basement membranes through interaction with various other components of the ECM (Argraves et al, 2003; Timpl et al, 2003). Expression of FBLN3 in condensing mesenchyme during development, which gives rise to bone and cartilage structures, implies an important role of this family member in skeletal development (Zhang and Marmorstein, 2010). In adult tissue FBLN3 is widely expressed in blood vessel walls, and in basement membranes of epithelial and endothelial cells (Giltay et al, 1999; Timpl et al, 2003; Zhang and Marmorstein, 2010). FBLN3 has been shown to stimulate expression of the tissue inhibitors of matrix metalloproteinases (TIMP)-1 and -3 (Klenotic et al, 2004; Kim et al, 2012), while inhibiting the expression of the matrix metalloproteinases MMP-2, -3, -7 and -9 (Albig et al, 2006; Kim et al, 2012), thus being directly involved in the regulation of tissue remodelling. In addition, FBLN3 has been reported to be involved in cell growth and tumour angiogenesis (Gallagher et al, 2005; Albig et al, 2006).

Fibulins are a relatively newly characterised group of ECM proteins and a link between FBLN3 and cancer has only been established over the past decade. Interestingly, the expression pattern of FBLN3 differs between tumour types, with up- or downregulation found depending on the cancer investigated (Yue et al, 2007; Camaj et al, 2009; Hu et al, 2009; Sadr-Nabavi et al, 2009; Seeliger et al, 2009; En-lin et al, 2010; Hwang et al, 2010; Nomoto et al, 2010; Wang et al, 2010; Hu et al, 2011, 2012, 2013; Kim et al, 2011; Song et al, 2011; Tong et al, 2011; Kim et al, 2012; Pass et al, 2012; Luo et al, 2013; Chen et al, 2014). FBLN3 therefore appears to have the potential to act as either tumour suppressor or oncogene depending on the cellular context.

More recently FBLN3 has been identified as a potential diagnostic and prognostic marker for malignant pleural mesothelioma (MPM) (Pass et al, 2012). Increased abundance of the FBLN3 protein was found in plasma and pleural effusion fluid of MPM patients, with high levels in effusions negatively correlated with survival. The same study also reported elevated FBLN3 expression in MPM primary tumours (Pass et al, 2012); however, a direct link between tumour FBLN3 expression and the secreted form of FBLN3 is yet to be made.

Towards this end, we investigated the expression and secretion of FBLN3 in MPM and benign mesothelial cell lines in vitro and in vivo. Our data confirm an upregulation of FBLN3 protein in MPM cell lines, which is mirrored by an increased secretion of the protein. In addition, we were able to confirm that levels of FBLN3 in pleural effusion may have prognostic value. However, a diagnostic role for FBLN3 levels in plasma was not supported by our data.

\section{MATERIALS AND METHODS}

Cell lines and protein lysis. Human MPM cell lines (H28, H226, H2452 and MSTO) and the immortalised normal cell line MeT-5A were obtained from the American Type Culture Collection (Manassas, VA, USA). The additional MPM lines MM05 (Relan et al, 2013), VMC23 (Kryeziu et al, 2013) and SPC111 (Schmitter et al, 1992) and the normal mesothelial line LP9 (Wu et al, 1982) were described previously. Cell lines were grown in the corresponding medium (RPMI-1640 for all MPM lines, DMEM for MeT-5A, M199 supplemented with $3.3 \mathrm{~nm}$ EGF, $400 \mathrm{~nm}$ hydrocortisone and $1 \%$ insulin-transferrin-selenium for LP9) supplemented with $10 \%$ fetal bovine serum (FBS) at $37^{\circ} \mathrm{C}$, $5 \% \mathrm{CO}_{2}$ and $95 \%$ humidity. All media and supplements were purchased from Life Technologies (Carlsbad, CA, USA) or Sigma Aldrich (St Louis, MO, USA). All cell lines were authenticated in September (H28, H2452, SPC111 and VMC23) or October (H226, H2052, MSTO, MM05, MeT-5A and LP9) 2014 at the Australian Genome Research Facility Ltd. (St Lucia, QLD, Australia) by short tandem repeat profiling using the GenePrint 10 System (Promega, Madison, WI, USA).

To assess secretion of FBLN3 by MPM cells in vitro, cells were first grown to $80 \%$ confluence in T25 flasks in medium containing FBS, then medium was replaced with $2 \mathrm{ml}$ serum-free medium. Cell-conditioned medium was collected after $24 \mathrm{~h}$, cell debris removed by $5 \mathrm{~min}$ centrifugation at 1200 r.p.m., and supernatants stored at $-80^{\circ} \mathrm{C}$. Protein lysates were prepared from the same cells by lysis in $300 \mu$ RIPA buffer as described previously (Linton et al, 2014). Protein concentration was determined using the Pierce BCA Protein Assay Kit (Thermo Scientific, Waltham, MA, USA) according to the manufacturer's instructions.

Mouse plasma and serum samples. Athymic $(n u / n u)$ mice were purchased from the Animal Resources Centre (Perth, WA, Australia) and injected subcutaneously in the left flank with $5 \times 10^{6} \mathrm{H} 226$ or $3 \times 10^{6} \mathrm{MSTO}$ cells in $100 \mu \mathrm{l}$ serum-free medium/ growth factor-reduced matrigel mix $(1: 1$, matrigel from $\mathrm{BD}$ Biosciences, Franklin Lakes, NJ, USA). Once tumours reached around $300 \mathrm{~mm}^{3}$, mice were killed and blood was collected via cardiac puncture into either empty or EDTA-containing tubes. Serum samples were allowed to clot for $60 \mathrm{~min}$ at room temperature before being further processed as for plasma samples (centrifugation at 2500 r.p.m. for $20 \mathrm{~min}$ ) and both were stored at $-80^{\circ} \mathrm{C}$. Samples were collected as part of animal studies approved by the Sydney Local Health District Animal Welfare Committee.

Patient samples. All samples were collected from patients who had provided written informed consent and the study was approved by the Human Research Ethics Committees at Concord Repatriation General Hospital (CH62/6/2009/078) and Royal Prince Alfred Hospital (X09-0322) in Sydney, the Ethical Committee of the Medical University of Vienna (\#904/2009) or the Southern Adelaide Clinical Human Research Ethics Committee (\#381.09).

In Sydney and Vienna blood was collected by venous puncture from (suspected) MPM patients 1 day before diagnostic procedure (video-assisted thoracoscopic surgery/biopsy) or radical surgery (extrapleural pneumonectomy) or from patients undergoing cardiac or aortic surgery for severe coronary artery (CAD) or aortic disease at participating centres. In Vienna additional control samples were collected from lung cancer patients. Blood was collected into $10 \mathrm{ml} \mathrm{K}{ }_{3}$ EDTA Vacutainers (BD Biosciences) which, within $30 \mathrm{~min}$ of blood collection, were centrifuged for $20 \mathrm{~min}$ at 2500 r.p.m. Plasma supernatant was stored in aliquots at $-80^{\circ} \mathrm{C}$. Pleural effusion samples were obtained from SA Pathology, Flinders Medical Centre and Institute of Medical and Veterinary Science SA. All pleural effusions were screened for diagnostic suitability by accessing pathology reports, with cytological diagnosis confirmed from subsequent radiological and/or surgical reports. MPM samples were obtained from consecutive patients presenting at Flinders Medical Centre between August 2011 and June 2014, while control samples were identified from the pathology database and collected until age and gender-matched samples from 30 patients in each group were identified. The median time from sample collection to confirmation of diagnosis was 2 days. Samples were spun at 1250 r.p.m. for $10 \mathrm{~min}$, and the resulting supernatant was stored immediately at $-80^{\circ} \mathrm{C}$. A summary of basic patient demographics is provided in Table 1. 


\begin{tabular}{|c|c|c|c|c|c|c|}
\hline & \multicolumn{2}{|c|}{ Sydney cohort } & \multicolumn{2}{|c|}{ Vienna cohort } & \multicolumn{2}{|c|}{ Pleural effusion cohort } \\
\hline & $\begin{array}{c}\text { MPM } \\
(N=37)\end{array}$ & $\begin{array}{c}\text { Non-MPM } \\
(N=32)\end{array}$ & $\begin{array}{c}\text { MPM } \\
(N=47)\end{array}$ & $\begin{array}{l}\text { Non-MPM } \\
(N=24)\end{array}$ & $\begin{array}{c}\text { MPM } \\
(N=30)\end{array}$ & $\begin{array}{c}\text { Non-MPM } \\
(N=60)\end{array}$ \\
\hline Median age (range) & $71.4(40-83)$ & $66.3(49-80)$ & $64(33-81)$ & $66.5(56-82)$ & $76(55-94)$ & $73.5(49-96)$ \\
\hline \multicolumn{7}{|l|}{ Gender } \\
\hline $\begin{array}{l}\text { Male } \\
\text { Female }\end{array}$ & $\begin{array}{r}32 \text { (86.5\%) } \\
5(13.5 \%)\end{array}$ & $\begin{array}{r}27(84.4 \%) \\
5(15.6 \%)\end{array}$ & $\begin{array}{l}35 \text { (74.5\%) } \\
12(25.5 \%)\end{array}$ & $\begin{array}{r}19(79.2 \%) \\
5(20.8 \%)\end{array}$ & $\begin{array}{r}26 \text { (86.7\%) } \\
4(13.3 \%)\end{array}$ & $\begin{array}{r}51(85 \%) \\
9(15 \%)\end{array}$ \\
\hline \multicolumn{7}{|l|}{ Diagnosis } \\
\hline $\begin{array}{l}\text { MPM } \\
\text { Pleural Plaques/Pleuritis } \\
\text { Adenocarcinoma } \\
\text { Lung } \\
\text { Breast } \\
\text { Endometrial } \\
\text { Colon } \\
\text { Other lung cancer } \\
\text { CAD }\end{array}$ & $37(100 \%)$ & 5 (15.6\%) & 47 (100\%) & $\begin{array}{l}10(41.7 \%) \\
4(16.7 \%) \\
3(12.5 \%) \\
7(29.2 \%)\end{array}$ & $30(100 \%)$ & $\begin{array}{r}30(50 \%) \\
27(45 \%) \\
1(1.6 \%) \\
1(1.6 \%) \\
1(1.6 \%)\end{array}$ \\
\hline \multicolumn{7}{|l|}{ MPM histotype } \\
\hline $\begin{array}{l}\text { Epithelioid } \\
\text { Biphasic } \\
\text { Sarcomatoid } \\
\text { Desmoplastic }\end{array}$ & $\begin{array}{c}26 \text { (70.3\%) } \\
8(21.6 \%) \\
2(5.4 \%) \\
1(2.7 \%) \\
\end{array}$ & & $\begin{array}{c}35 \text { (74.5\%) } \\
7 \text { (14.9\%) } \\
4 \text { (8.5\%) } \\
1(2.1 \%) \\
\end{array}$ & & $\begin{array}{c}27(90 \%) \\
2 \text { (6.7\%) } \\
1(3.3 \%) \\
0 \\
\end{array}$ & \\
\hline
\end{tabular}

FBLN3 ELISA. FBLN3 levels were determined using the human FBLN3 ELISA (\#SEF422Hu, USCN Life Science Inc., Wuhan, China) according to the manufacturer's instructions at the centres at which the respective samples were collected. Cell lysates were diluted $1: 2$, cell-conditioned medium $1: 4$, plasma samples were either diluted 1:3 (Sydney cohort and mouse plasma) or used undiluted (Vienna cohort), and pleural effusion samples were diluted $1: 10$ in phosphate-buffered saline. Pleural effusion samples that showed concentrations higher than the highest standard were diluted further and measured again. All samples were measured in duplicate. FBLN3 levels were calculated and expressed as either $\mathrm{ng} \mathrm{mg}^{-1}$ total protein (cell lysates and cell-conditioned medium) or $\mathrm{ng} \mathrm{ml}^{-1}$ (plasma and pleural effusion). Samples with readings below those of the lowest standard were reported as $1.56 \mathrm{ng} \mathrm{ml}^{-1}$.

Statistical analysis. FBLN3 levels are reported as mean \pm s.d., and significant differences in FBLN3 levels were determined using independent samples $t$-test. Receiver operating characteristics curve analysis was used to determine the accuracy of FBLN3 to predict correct diagnosis. Survival was calculated from date of diagnosis until date on which analysis was performed, with patients still alive at this time point being censored. The Kaplan-Meier log rank method was used to assess association between FBLN3 and survival, and if significant in univariate analysis, multivariate coxregression was performed to investigate the value independent prognostic factor.

\section{RESULTS}

MPM cells express and secrete FBLN3 in vitro. FBLN3 expression was detected in all benign mesothelial (expression range: $4.99-10.51 \mathrm{ng} \mathrm{mg}^{-1}$ ) and MPM lines (expression range: $8.85-18.78 \mathrm{ng} \mathrm{mg}^{-1}$, mean expression $13.89 \pm 3.94 \mathrm{ng} \mathrm{mg}^{-1}$ ). There was no statistically significant difference between levels in the two groups $(P=0.093)$ (Figure $1 \mathrm{~A})$. Among MPM cell lines, the average expression was higher in cells derived from tumours of epithelioid histology $\left(16.18 \pm 3.46 \mathrm{ng} \mathrm{mg}^{-1}\right)$ than in those from biphasic (mixed) histology $\left(10.64 \pm 2.04 \mathrm{ng} \mathrm{mg}^{-1}\right)$. Although not reaching statistical significance $(P=0.066)$, this trend suggests a possible correlation between histological subtype and expression of FBLN3. Assessment of secreted FBLN3 levels in cell-conditioned medium (Figure 1B) revealed a correlation between cellular FBLN3 expression and secretion of the protein (Spearman $r=0.78$, $P=0.017$, Figure 1C), with a non-statistically significant trend towards higher secretion observed in cells derived from epithelioid tumours $(P=0.26)$.

FBLN3 is secreted by MPM cells in vivo. To confirm MPM cells as the origin of circulating FBLN3, protein levels were measured in serum and plasma collected from H226 and MSTO xenograftbearing mice. Although FBLN3 was not detectable in serum samples, 3/3 plasma samples from H226-xenografts and 2/3 plasma samples from MSTO-xenografts were positive for human FBLN3 (Figure 1D). Although from a small number of samples, the in vivo data are consistent with the in vitro observation that MPM cells actively secrete FBLN3, and suggest that MPM cells contribute to the FBLN3 levels found in the blood. The lack of detection of FBLN3 in serum samples is in line with previous findings of low abundance of FBLN3 in serum, which may be attributed to thrombin-mediated cleavage of FBLN3 (Pass et al, 2012).

Levels of FBLN3 in MPM patient plasma have little diagnostic value. Abundance of FBLN3 was assessed in two independent cohorts of MPM patients and controls. The mean levels of FBLN3 in plasma from MPM patients were $16.10 \pm 1.87 \mathrm{ng} \mathrm{ml}^{-1}$ (Sydney) and $11.51 \pm 1.73 \mathrm{ng} \mathrm{ml}^{-1}$ (Vienna), and were lower than those previously reported (Pass et al, 2012; Creaney et al, 2014; Hooper et al, 2015). There was no significant difference in the FBLN3 levels observed in the two cohorts $(P=0.077$ for MPM and $P=0.77$ for non-MPM samples). Analysis of the Sydney cohort showed a modest but statistically significant increase in circulating FBLN3 in MPM patients compared with patients with pleural plaques or $\operatorname{CAD}\left(16.10 \pm 1.87\right.$ vs $10.92 \pm 1.54 \mathrm{ng} \mathrm{ml}^{-1}, P=0.039$, Figure $\left.2 \mathrm{~A}\right)$, whereas analysis of the Vienna cohort did not $(11.51 \pm 1.73 \mathrm{vs}$ $11.97 \pm 3.56 \mathrm{ng} \mathrm{ml}^{-1}, P=0.897$; Figure 2B). Receiver operating characteristics curve analyses showed an overall accuracy of $63.2 \%$ (95\% CI: $50.1-76.4 \%, P=0.06$, Figure 2C) for correct classification as MPM for the Sydney cohort and $56.2 \%$ (95\% CI: $41.5-71.0 \%$, $P=0.39$, Figure 2D) for the Vienna cohort. At the lower cut-off of $29 \mathrm{ng} \mathrm{ml}^{-1}$ (Pass et al, 2012), FBLN3 in the Sydney and Vienna 

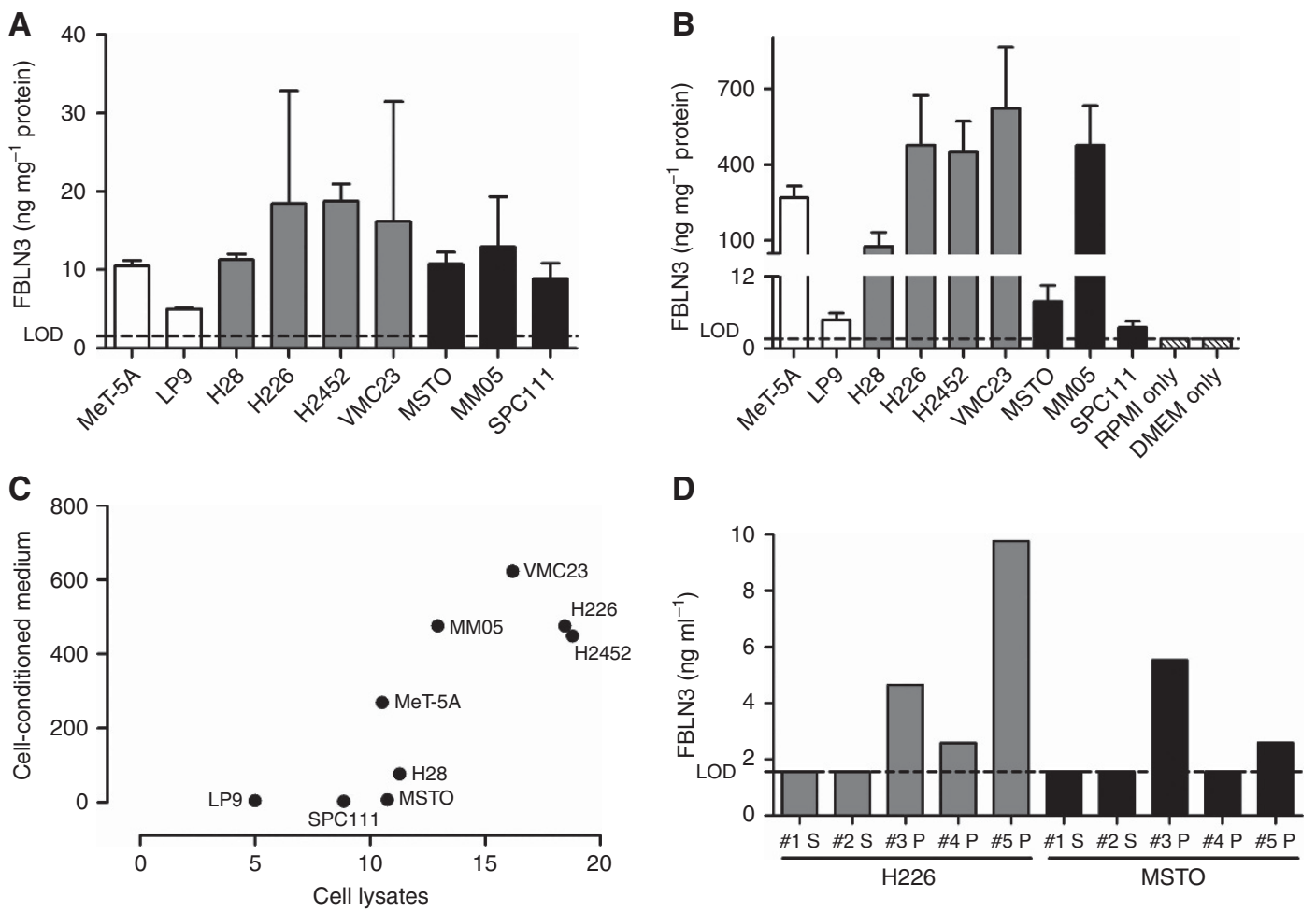

Figure 1. MPM cell lines secrete FBLN3. Cellular (A) and secreted (B) levels of FBLN3 in MPM cell lines (grey bars=epithelioid; black bars=biphasic) and benign mesothelial cells (white bars). (C) Relationship between the amount of secreted FBLN3 and cellular FBLN3 levels. (D) FBLN3 levels in the plasma (P) or serum (S) of mice bearing human MPM xenografts of epithelioid (grey bars) or biphasic (black bars) origin. Lower limit of detection (LOD) of the ELISA is indicated by the dotted line, medium only (RPMI or DMEM) controls are shown in patterned white bars.
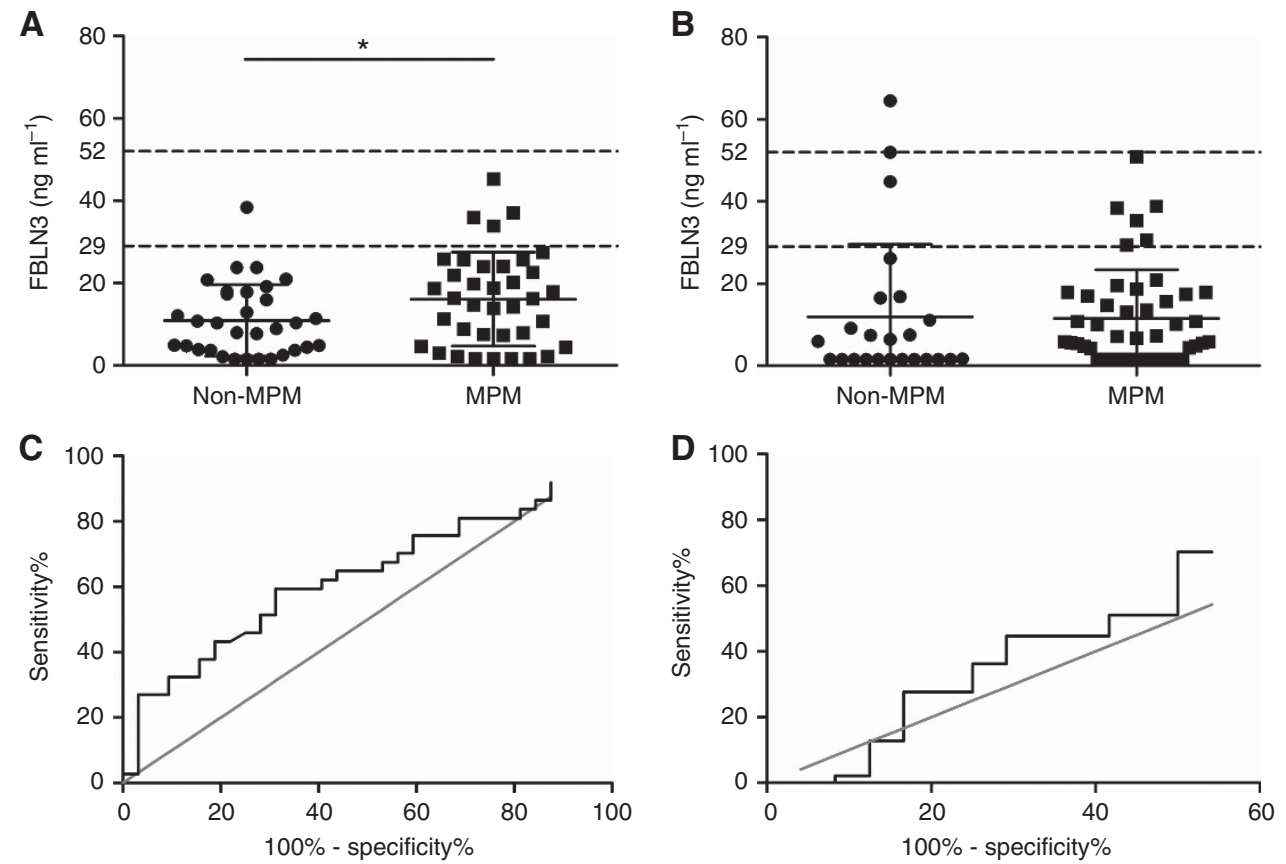

Figure 2. FBLN3 in patient plasma. Plasma FBLN3 protein levels in the Sydney (A) and Vienna cohort (B). Mean levels in both cohorts were below those previously reported. Mean \pm s.d. are represented by the lines in the scatter plots, and the cut-offs applied in the original study (Pass et al, 2012) are indicated by dotted lines. The diagnostic accuracy of plasma FBLN3 was low in both investigated cohorts: (C) Sydney cohort AUC $=0.63$ (95\% Cl: 0.50-0.76); and (D) Vienna cohort $\mathrm{AUC}=0.56$ (95\% Cl: 0.41-0.71).

series showed a sensitivity of $13.5 \%$ and a specificity of $96.9 \%$, and a sensitivity of $12.7 \%$ and a specificity of $87.5 \%$, respectively. Differences in circulating FBLN3 levels between patients with different histological subtypes or associations with survival were not observed (data not shown).
High FBLN3 levels in pleural effusion fluid are associated with poor prognosis. Mean FBLN3 levels in MPM effusions were $628.9 \pm 853.8 \mathrm{ng} \mathrm{ml}^{-1}$ and while comparable to those previously published $\left(636 \mathrm{ng} \mathrm{ml}^{-1}\right.$ ) (Pass et al, 2012; Creaney et al, 2014), significant differences between effusions from MPM patients and 

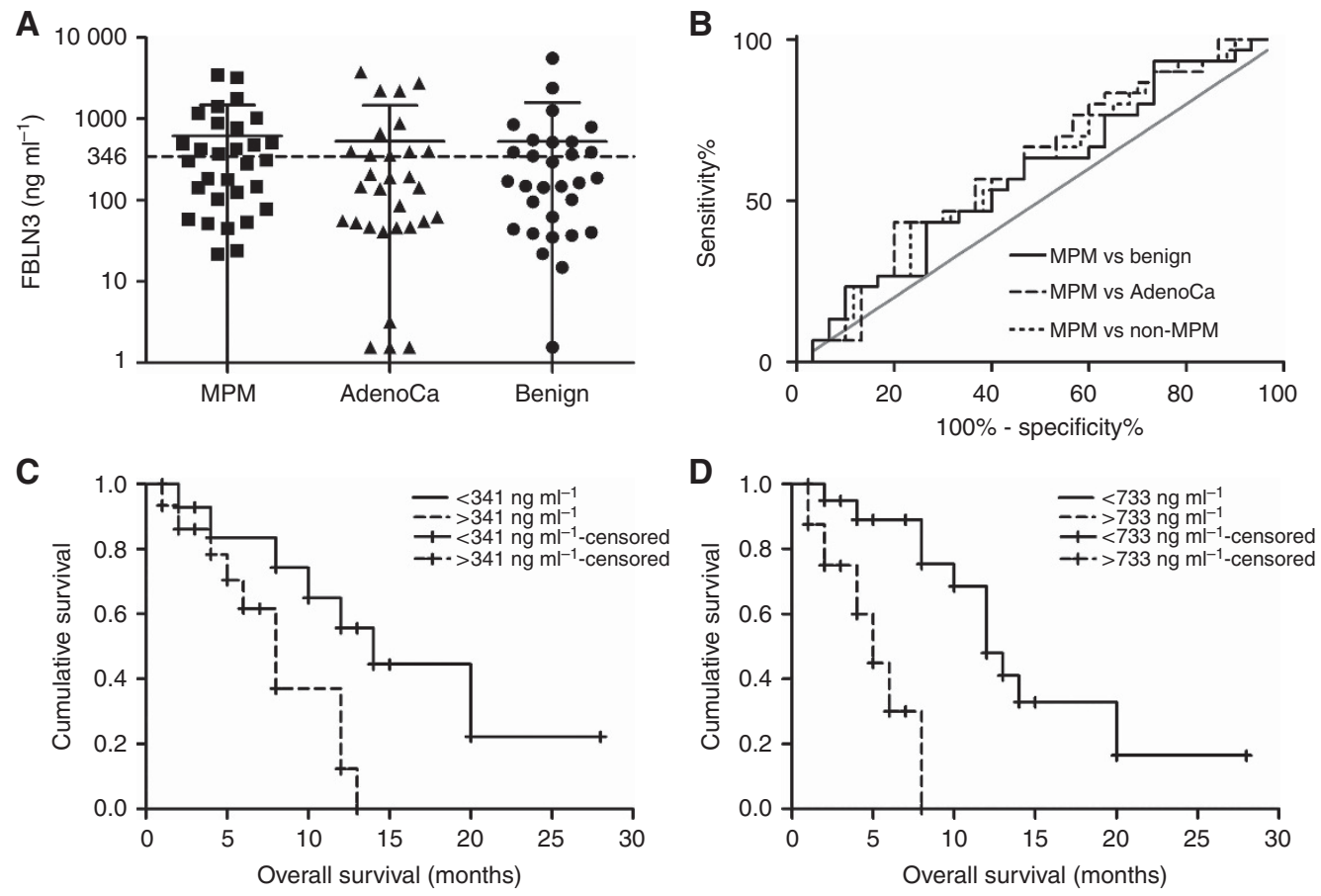

Figure 3. Pleural effusion FBLN3. (A) FBLN3 was measured in the pleural effusion in MPM and non-MPM conditions. The lines in the scatter plot represent the mean \pm s.d. (B) Receiver operating characteristics analysis of FBLN3 levels in the different physiological conditions. (C, D) Kaplan-Meier analysis of FBLN3 in MPM patients using the median FBLN3 level (C) or the cut-off applied in the original study (Pass et al, 2012) (D).

patients with other conditions were not observed (Figure 3A). Receiver operating characteristics curve analyses showed low accuracy for correct classification of MPM patients in comparisons with all other groups (Figure 3B). Survival analyses in the MPM subset did not show any correlation between clinical prognostic factors (histological subtype, age and gender), but this may be attributed to the relatively small numbers in the various subgroups (Table 1). Low levels of FBLN3 were, however, significantly associated with prolonged survival, and this was independent of whether the median for this group (Figure 3C) or the previously published cut-off (Pass et al, 2012) (Figure 3D) was used. In multivariate analyses including histological subtype, age and gender as covariates, FBLN3 remained significant at both cut-offs with hazard ratios (HRs) of 4.03 (95\% CI: 1.215-13.36) and 9.92 (95\% CI: 2.14-45.93), respectively.

\section{DISCUSSION}

A recent study describing elevated FBLN3 levels in MPM patients reported that FBLN3 is overexpressed in tumour tissue, with higher levels also present in pleural effusion fluid and plasma (Pass et al, 2012). These results suggest a possible oncogenic role for FBLN3 in MPM. Our studies with MPM cell lines in vitro and xenografted tumours in vivo support these previous findings in MPM tissue, and suggest that MPM cells express and secrete FBLN3, and are a source of FBLN3 in patient plasma samples. Interestingly, while FBLN3 was also found to be elevated in pancreatic (Camaj et al, 2009; Seeliger et al, 2009), cervical (En-lin et al, 2010; Song et al, 2011) and brain cancer (Hu et al, 2009, 2011, 2012), in the majority of cancer types (Yue et al, 2007; Sadr-Nabavi et al, 2009; Hwang et al, 2010; Nomoto et al, 2010; Wang et al, 2010; Kim et al, 2011; Tong et al, 2011; Kim et al, 2012; Luo et al, 2013; Chen et al, 2014) the protein is downregulated. These opposing findings are further complicated in malignant glioma where FBLN3 was found to be upregulated compared with normal tissue, but at the same time positively correlated with prolonged survival (Hu et al, 2009, 2011, 2012). Together these data suggest FBLN3 may have varying context- and tissue-dependent roles. This is further highlighted by the involvement of FBLN3 in the regulation of Akt signalling in different types of cancer. Although epigenetic silencing of FBLN3 in nasopharyngeal carcinoma (NPC) leads to activation of the Akt signalling pathway (Hwang et al, 2010), in pancreatic cancer overexpression of FBLN3 also results in Akt activation (Camaj et al, 2009). These two seemingly opposing effects are thought to be brought about by two different mechanisms. On the one hand, FBLN3 protein has been suggested to interfere with phosphorylation and therefore activation of Akt, meaning that low FBLN3 results in an increase in Akt signalling leading to increased migration and invasion of NPC cells (Hwang et al, 2010). On the other hand, in pancreatic cancer, FBLN3 was shown to indirectly stimulate Akt phosphorylation through binding to and activating signalling through the EGF receptor (EGFR) (Camaj et al, 2009). In the context of MPM one can speculate that similar to the scenario in pancreatic cancer the elevated expression of FBLN3 together with an overexpression of EGFR (observed in 40-60\% of MPM cases (Destro et al, 2006; Edwards et al, 2006; Gaafar et al, 2010; Rena et al, 2011)) may act in concert to lead to the increased activation of Akt signalling frequently observed in MPM (Altomare et al, 2005). Further investigation is needed to determine whether FBLN3 might therefore act as an oncogene contributing to the invasive nature of MPM.

The initial report describing FBLN3 overexpression in MPM suggested that this can serve as a reliable diagnostic and prognostic biomarker of the disease (Pass et al, 2012). However, these promising findings have yet to be fully validated. The original study reported elevated levels of cell-free FBLN3 in both plasma and pleural effusion fluid which were able to separate, with very high sensitivity and specificity, MPM patients from healthy individuals and patients with effusions due to other malignancies (Pass et al, 2012). Three validation studies (Corradi et al, 2013; Agha et al, 2014; Creaney et al, 2014) confirmed that 
plasma levels of FBLN3 in MPM were elevated, but sensitivity and specificity of the assay were either notably lower or cut-off levels used to determine these were different to those originally applied, making direct comparisons difficult. In line with these data, we found plasma FBLN3 to be significantly elevated in one of our two plasma series. Although overall levels of FBLN3 were much lower than those reported in the first (Pass et al, 2012) and one subsequent (Agha et al, 2014) report, they were more comparable to those reported in the two other validation studies (Corradi et al, 2013; Creaney et al, 2014). Average FBLN3 levels were lower than the diagnostic cut-off used by Pass et al. In addition, sensitivity and specificity of the assay were lower than those in the original study (Pass et al, 2012) and did not reach the cut-off of $80 \%$ for both sensitivity and specificity which would classify this protein as a good diagnostic marker according to International Mesothelioma Interest Group guidelines (Husain et al, 2013). Most recently, the South West Area Mesothelioma and Pemetrexed Trial also reported on FBLN3 in plasma from MPM patients (Hooper et al, 2015). Although this trial was not designed to assess the diagnostic potential of any of the investigated biomarkers, the investigators also found FBLN3 levels to be considerably lower than reported by Pass et al (2012), with only $8 \%$ of patients having levels higher than the proposed diagnostic cut-off of $56 \mathrm{ng} \mathrm{ml}^{-1}$ (Hooper et al, 2015).

Creaney et al (2014) also investigated FBLN3 in pleural effusion samples. Although the authors did not find significant differences in FBLN3 levels between patient groups, high FBLN3 pleural effusion levels were independently associated with shorter survival (HR 2.05). Similarly we did not observe significant differences between the levels of FBLN3 in the various samples of malignant pleural effusions, but confirmed that high effusion FBLN3 levels were independently associated with short survival. Thus FBLN3 in pleural fluid may represent a useful prognostic marker in MPM; however, the initial findings supporting FBLN3 as a reliable diagnostic marker could not be reproduced. The presence of elevated levels of FBLN3 in pleural effusion of MPM patients together with experimental data suggesting that FBLN3 is actively secreted by FBLN3-overexpressing MPM tumour cells clearly asks for additional experimental studies.

The current study has some limitations: FBLN3 assessment in plasma and serum from xenograft-bearing mice, while limited by a relatively small sample size, nevertheless showed that MPM tumour cells actively secrete FBLN3 in vivo. The sample sizes of the human material (patient cohorts) were also relatively small; however, the results obtained in the two independent series of plasma samples obtained at different institutions were comparable. In addition, given its retrospective nature, the study is bound by the inherent limitations of such studies. The use of patients undergoing cardiac surgery as controls could also be seen as a weakness of the study, since patients with proven asbestos exposure would be considered the more appropriate control. However, in particular for Australia it is known that due to the large amounts of asbestos in the natural environment and the heavy use of asbestos in the past resulting in large amounts also being present in the built environment the majority of citizens have been exposed to at least low levels of asbestos (knowingly or unknowingly) in a non-occupational setting (LaDou et al, 2010; Olsen et al, 2011). We therefore assume the phenomenon of (often unknown) low level asbestos exposure also to be reflected in our control series, and this is particularly true for the cardiac patients in the Sydney series. Despite these limitations our data further confirm the prognostic value of pleural effusion FBLN3, but questions the diagnostic value of this protein in plasma of MPM patients. The results of the present study contribute to a growing literature on the value of FBLN3 as a biomarker in MPM, and underline the need for prospective validation.

\section{ACKNOWLEDGEMENTS}

We thank the University of Queensland Thoracic Research Centre (The Prince Charles Hospital, Brisbane, Australia), Walter Berger (Institute of Cancer Research, Medical University of Vienna, Austria) and Steven Gray (Thoracic Oncology Research, Trinity College Dublin, Ireland) for kindly providing MM05, VMC23 and LP9 cells, respectively. We also thank Andreas Wagner and Barbara Dekan for technical assistance with the experiments. This study was supported by the following grants: Cancer Institute NSW program grant 11/TPG/3-06 to NvZ and GR; Flinders Medical Centre Foundation grant to SK; KTIA AIK 12-1-2013-0041 to BD and VL; OTKA K109626 and OTKA K108465 to BD and BH; ÖNB Jubiläumsfondsprojekt Nr. 14043 to $\mathrm{BD}$ and VL; and the Vienna Fund for Innovative Interdisciplinary Cancer Research to BD and VL. MBK was supported by the Swift Family Bequest and Mr Jim Tully Fellowship. The funding sources had no role in the design and conduct of the study or in the preparation of the manuscript.

\section{CONFLICT OF INTEREST}

The authors declare no conflict of interest.

\section{REFERENCES}

Agha MA, El-Habashy MM, El-Shazly RA (2014) Role of fibulin-3 in the diagnosis of malignant mesothelioma. Egypt J Chest Dis Tuberc 63(1): 99-105.

Albig AR, Neil JR, Schiemann WP (2006) Fibulins 3 and 5 antagonize tumor angiogenesis in vivo. Cancer Res 66(5): 2621-2629.

Altomare DA, You H, Xiao G-H, Ramos-Nino ME, Skele KL, De Rienzo A, Jhanwar SC, Mossman BT, Kane AB, Testa JR (2005) Human and mouse mesotheliomas exhibit elevated AKT//PKB activity, which can be targeted pharmacologically to inhibit tumor cell growth. Oncogene 24(40): 6080-6089.

Argraves WS, Greene LM, Cooley MA, Gallagher WM (2003) Fibulins: physiological and disease perspectives. EMBO Rep 4(12): 1127-1131.

Camaj P, Seeliger H, Ischenko I, Krebs S, Blum H, De Toni EN, Faktorova D, Jauch KW, Bruns CJ (2009) EFEMP1 binds the EGF receptor and activates MAPK and Akt pathways in pancreatic carcinoma cells. Biol Chem 390(12): 1293-1302.

Chen X, Meng J, Yue W, Yu J, Yang J, Yao Z, Zhang L (2014) Fibulin-3 suppresses Wnt/beta-catenin signaling and lung cancer invasion. Carcinogenesis 35(8): 1707-1716.

Corradi M, Goldoni M, Alinovi R, Tiseo M, Ampollini L, Bonini S, Carbognani P, Casalini A, Mutti A (2013) YKL-40 and Mesothelin in the blood of patients with malignant mesothelioma, lung cancer and asbestosis. Anticancer Res 33(12): 5517-5524.

Creaney J, Dick IM, Meniawy TM, Leong SL, Leon JS, Demelker Y, Segal A, Musk AW, Lee YCG, Skates SJ, Nowak AK, Robinson BWS (2014) Comparison of fibulin-3 and mesothelin as markers in malignant mesothelioma. Thorax 69(10): 895-902.

Destro A, Ceresoli GL, Falleni M, Zucali PA, Morenghi E, Bianchi P, Pellegrini C, Cordani N, Vaira V, Alloisio M, Rizzi A, Bosari S, Roncalli M (2006) EGFR overexpression in malignant pleural mesothelioma. An immunohistochemical and molecular study with clinico-pathological correlations. Lung Cancer 51(2): 207-215.

Edwards JG, Swinson DE, Jones JL, Waller DA, O’Byrne KJ (2006) EGFR expression: associations with outcome and clinicopathological variables in malignant pleural mesothelioma. Lung Cancer 54(3): 399-407.

En-lin S, Sheng-guo C, Hua-qiao W (2010) The expression of EFEMP1 in cervical carcinoma and its relationship with prognosis. Gynecol Oncol 117(3): 417-422.

Gaafar R, Bahnassy A, Abdelsalam I, Kamel MM, Helal A, Abdel-Hamid A, Eldin NA, Mokhtar N (2010) Tissue and serum EGFR as prognostic factors in malignant pleural mesothelioma. Lung Cancer 70(1): 43-50.

Gallagher WM, Currid CA, Whelan LC (2005) Fibulins and cancer: friend or foe? Trends Mol Med 11(7): 336-340. 
Giltay R, Timpl R, Kostka G (1999) Sequence, recombinant expression and tissue localization of two novel extracellular matrix proteins, fibulin-3 and fibulin-4. Matrix Biol 18(5): 469-480.

Hooper CE, Lyburn ID, Searle J, Darby M, Hall T, Hall D, Morley A, White P, Rahman NM, De Winton E, Clive A, Masani V, Arnold DT, Dangoor A, Guglani S, Jankowska P, Lowndes SA, Harvey JE, Braybrooke JP, Maskell NA (2015) The South West Area Mesothelioma and Pemetrexed trial: a multicentre prospective observational study evaluating novel markers of chemotherapy response and prognostication. Br J Cancer 112(7): 1175-1182.

Hu B, Nandhu MS, Sim H, Agudelo-Garcia PA, Saldivar JC, Dolan CE, Mora ME, Nuovo GJ, Cole SE, Viapiano MS (2012) Fibulin-3 promotes glioma growth and resistance through a novel paracrine regulation of Notch signaling. Cancer Res 72(15): 3873-3885.

Hu B, Thirtamara-Rajamani KK, Sim H, Viapiano MS (2009) Fibulin-3 is uniquely upregulated in malignant gliomas and promotes tumor cell motility and invasion. Mol Cancer Res 7(11): 1756-1770.

Hu Y, Pioli PD, Siegel E, Zhang Q, Nelson J, Chaturbedi A, Mathews MS, Ro DI, Alkafeef S, Hsu N, Hamamura M, Yu L, Hess KR, Tromberg BJ, Linskey ME, Zhou YH (2011) EFEMP1 suppresses malignant glioma growth and exerts its action within the tumor extracellular compartment. Mol Cancer 10: 123.

Hu YJ, Vo C, Li ZZ, Ke C, Ru N, Hess KR, Linskey ME, Zhou YH (2013) Efemp1 attenuates Egfr signaling activities and the prognostic effect of Efempldepends on the level of Egfr expression in gliomas. Neuro Oncol 15: $18-18$.

Husain AN, Colby T, Ordonez N, Krausz T, Attanoos R, Beasley MB, Borczuk AC, Butnor K, Cagle PT, Chirieac LR, Churg A, Dacic S, Fraire A, Galateau-Salle F, Gibbs A, Gown A, Hammar S, Litzky L, Marchevsky AM, Nicholson AG, Roggli V, Travis WD, Wick M (2013) Guidelines for pathologic diagnosis of malignant mesothelioma: 2012 update of the consensus statement from the International Mesothelioma Interest Group. Arch Pathol Lab Med 137(5): 647-667.

Hwang CF, Chien CY, Huang SC, Yin YF, Huang CC, Fang FM, Tsai HT, Su LJ, Chen CH (2010) Fibulin-3 is associated with tumour progression and a poor prognosis in nasopharyngeal carcinomas and inhibits cell migration and invasion via suppressed AKT activity. J Pathol 222(4): 367-379.

Kim EJ, Lee SY, Woo MK, Choi SI, Kim TR, Kim MJ, Kim KC, Cho EW, Kim IG (2012) Fibulin-3 promoter methylation alters the invasive behavior of non-small cell lung cancer cell lines via MMP-7 and MMP-2 regulation. Int J Oncol 40(2): 402-408.

Kim YJ, Yoon HY, Kim SK, Kim YW, Kim EJ, Kim IY, Kim WJ (2011) EFEMP1 as a novel DNA methylation marker for prostate cancer: array-based DNA methylation and expression profiling. Clin Cancer Res 17(13): 4523-4530.

Klenotic PA, Munier FL, Marmorstein LY, Anand-Apte B (2004) Tissue inhibitor of metalloproteinases-3 (TIMP-3) is a binding partner of epithelial growth factor-containing fibulin-like extracellular matrix protein 1 (EFEMP1): implications for macular degenerations. J Biol Chem 279(29): 30469-30473.

Kryeziu K, Jungwirth U, Hoda MA, Ferk F, Knasmuller S, Karnthaler-Benbakka C, Kowol CR, Berger W, Heffeter P (2013) Synergistic anticancer activity of arsenic trioxide with erlotinib is based on inhibition of EGFR-mediated DNA double-strand break repair. Mol Cancer Ther 12(6): 1073-1084.

LaDou J, Castleman B, Frank A, Gochfeld M, Greenberg M, Huff J, Joshi TK, Landrigan PJ, Lemen R, Myers J, Soffritti M, Soskolne CL, Takahashi K, Teitelbaum D, Terracini B, Watterson A (2010) The case for a global ban on asbestos. Environ Health Perspect 118(7): 897-901.

Linton A, Cheng YY, Griggs K, Kirschner MB, Gattani S, Srikaran S, Chuan-Hao Kao S, McCaughan BC, Klebe S, van Zandwijk N, Reid G (2014) An RNAi-based screen reveals PLK1, CDK1 and NDC80 as potential therapeutic targets in malignant pleural mesothelioma. Br J Cancer 110(2): 510-519.

Luo R, Zhang M, Liu L, Lu S, Zhang CZ, Yun J (2013) Decrease of fibulin-3 in hepatocellular carcinoma indicates poor prognosis. PloS one 8(8): e70511.
Nomoto S, Kanda M, Okamura Y, Nishikawa Y, Qiyong L, Fujii T, Sugimoto H, Takeda S, Nakao A (2010) Epidermal growth factorcontaining fibulin-like extracellular matrix protein 1, EFEMP1, a novel tumor-suppressor gene detected in hepatocellular carcinoma using double combination array analysis. Ann Surg Oncol 17(3): 923-932.

Olsen NJ, Franklin PJ, Reid A, de Klerk NH, Threlfall TJ, Shilkin K, Musk B (2011) Increasing incidence of malignant mesothelioma after exposure to asbestos during home maintenance and renovation. Med J Aust 195(5): 271-274.

Pass HI, Levin SM, Harbut MR, Melamed J, Chiriboga L, Donington J, Huflejt M, Carbone M, Chia D, Goodglick L, Goodman GE, Thornquist MD, Liu G, de Perrot M, Tsao MS, Goparaju C (2012) Fibulin-3 as a blood and effusion biomarker for pleural mesothelioma. N Engl J Med 367(15): 1417-1427.

Relan V, Morrison L, Parsonson K, Clarke BE, Duhig EE, Windsor MN, Matar KS, Naidoo R, Passmore L, McCaul E, Courtney D, Yang IA, Fong KM, Bowman RV (2013) Phenotypes and karyotypes of human malignant mesothelioma cell lines. PloS One 8(3): e58132.

Rena O, Boldorini LR, Gaudino E, Casadio C (2011) Epidermal growth factor receptor overexpression in malignant pleural mesothelioma: prognostic correlations. J Surg Oncol 104(6): 701-705.

Sadr-Nabavi A, Ramser J, Volkmann J, Naehrig J, Wiesmann F, Betz B, Hellebrand H, Engert S, Seitz S, Kreutzfeld R, Sasaki T, Arnold N, Schmutzler R, Kiechle M, Niederacher D, Harbeck N, Dahl E, Meindl A (2009) Decreased expression of angiogenesis antagonist EFEMP1 in sporadic breast cancer is caused by aberrant promoter methylation and points to an impact of EFEMP1 as molecular biomarker. Int $J$ Cancer 124(7): 1727-1735.

Schmitter D, Lauber B, Fagg B, Stahel RA (1992) Hematopoietic growth factors secreted by seven human pleural mesothelioma cell lines: interleukin-6 production as a common feature. Int J Cancer 51(2): 296-301.

Seeliger H, Camaj P, Ischenko I, Kleespies A, De Toni EN, Thieme SE, Blum H, Assmann G, Jauch KW, Bruns CJ (2009) EFEMP1 expression promotes in vivo tumor growth in human pancreatic adenocarcinoma. Mol Cancer Res 7(2): 189-198.

Song EL, Hou YP, Yu SP, Chen SG, Huang JT, Luo T, Kong LP, Xu J, Wang HQ (2011) EFEMP1 expression promotes angiogenesis and accelerates the growth of cervical cancer in vivo. Gynecol Oncol 121(1): 174-180.

Timpl R, Sasaki T, Kostka G, Chu ML (2003) Fibulins: a versatile family of extracellular matrix proteins. Nat Rev Mol Cell Biol 4(6): 479-489.

Tong JD, Jiao NL, Wang YX, Zhang YW, Han F (2011) Downregulation of fibulin-3 gene by promoter methylation in colorectal cancer predicts adverse prognosis. Neoplasma 58(5): 441-448.

Wang R, Zhang YW, Chen LB (2010) Aberrant promoter methylation of FBLN-3 gene and clinicopathological significance in non-small cell lung carcinoma. Lung Cancer 69(2): 239-244.

Wu YJ, Parker LM, Binder NE, Beckett MA, Sinard JH, Griffiths CT, Rheinwald JG (1982) The mesothelial keratins: a new family of cytoskeletal proteins identified in cultured mesothelial cells and nonkeratinizing epithelia. Cell 31(3 Pt 2): 693-703.

Yue W, Dacic S, Sun Q, Landreneau R, Guo M, Zhou W, Siegfried JM, Yu J, Zhang L (2007) Frequent inactivation of RAMP2, EFEMP1 and Dutt1 in lung cancer by promoter hypermethylation. Clin Cancer Res 13(15 Pt 1): 4336-4344.

Zhang Y, Marmorstein LY (2010) Focus on molecules: fibulin-3 (EFEMP1). Exp Eye Res 90(3): 374-375.

Zhou YH (2013) EFEMP1 (EGF containing fibulin-like extracellular matrix protein 1). Atlas Genet Cytogenet Oncol Haematol 17(2): 115-120.

This work is published under the standard license to publish agreement. After 12 months the work will become freely available and the license terms will switch to a Creative Commons AttributionNonCommercial-Share Alike 4.0 Unported License. 